\title{
Interactive comment on "Should altitudinal gradients of temperature and precipitation inputs be inferred from key parameters in snow-hydrological models?" by Denis Ruelland
}

\section{Denis Ruelland \\ denis.ruelland@um2.fr \\ Received and published: 3 February 2020}

\section{Dear Editor,}

Please find enclosed the revised version of the paper \#HESS-2019-556, entitled "Should altitudinal gradients of temperature and precipitation inputs be inferred from key parameters in snow-hydrological models?" by D. Ruelland.

I would like to sincerely thank the referee for the time and effort he/she spent in reading the initial manuscript and for making many clear, pertinent and constructive suggestions for improvement. This helped a lot to re-write the paper. 
As the number of revisions and remarks were numerous, significant modifications were brought to the manuscript. This led me to rewrite some parts of the paper and to modify (or add) figures. Please refer to the revised manuscript in which modifications have been inserted in track changes mode in the document. Please, find my responses and modifications to manuscript in a supplement file as a detailed point-by-point reply to the referee comments. For clarification, remarks of referee are formatted in grey italic, while my answers (response and modifications to manuscript) are formatted in blue. Changes on the manuscript have been inserted in track change mode in the manuscript.

I hope the modifications brought to the manuscript have raised its scientific quality.

\section{Best regards, D. Ruelland}

Please also note the supplement to this comment:

https://www.hydrol-earth-syst-sci-discuss.net/hess-2019-556/hess-2019-556-AC1supplement.pdf

Interactive comment on Hydrol. Earth Syst. Sci. Discuss., https://doi.org/10.5194/hess-2019556, 2019. 